\title{
A Streamlined Probabilistic Methodology for Risk Assessment of Early Cracking in Airfield Concrete Pavement Design
}

\author{
F. D’Amico ${ }^{1}$, L. Bianchini Ciampoli ${ }^{1}$ and F. Tosti ${ }^{2}$ \\ ${ }^{1}$ Department of Engineering, Roma Tre University, Via Vito Volterra 62, 00146, \\ Rome, Italy; email: fabrizio.damico@uniroma3.it; \\ luca.bianchiniciampoli@uniroma3.it \\ ${ }^{2}$ School of Computing and Engineering, University of West London (UWL), St Mary's \\ Road, Ealing, W5 5RF, London, UK; email: Fabio.Tosti@uwl.ac.uk
}

\begin{abstract}
Early-age cracking is a major issue in design and construction of concrete pavements. This occurrence depends upon various factors i.e., design features, concrete mixture materials, jointing techniques and environmental circumstances. This may however occur despite adequate design, construction and jointing operations are correctly followed. Interactions of the above key factors are assessed using comprehensive analytical methods which are demanding in terms of data input and computational requirements. This research presents a streamlined probabilistic methodology for probabilistic risk assessment of early cracking in airfield concrete pavement design. The method provides a strength-to-stress ratio (SSR) index for identification of critical cracking conditions. A risk chart is presented with reference to the designed SSR value, and the required reliability level of the design process.
\end{abstract}

Keywords: early cracking; concrete pavement design; probabilistic risk assessment; strength-to-stress ratio (SSR); airport apron.

\section{INTRODUCTION}

Thermal expansion and contraction affect deformation in concrete slabs due to temperature and moisture gradient between surface and bottom interfaces. Use of joints is crucial to regulate formation of cracks, as slab self-weight counteracting this process cause steady cracking in concrete. To this effect, contraction joints are specifically used $(A C P A, 1991)$. Another important operation is the identification of the timing required to provide saw cuts. Saw cuts are used to create control joints in concrete, which help control where cracking occurs due to shrinkage. (ACPA, 1993; Okamoto et al, 1994)

However, it is frequent to observe early distress at the construction stage of concrete pavements, despite a large availability of specialised survey equipment ( $F A A$, 2016; Voigt, 2002). To this effect, negligence at the construction stage process or poorly predicted information on environmental conditions may contribute to early cracking in slabs (Delatte, 2014). Early cracking or uncontrolled cracking in concrete is defined as the development of cracks throughout a concrete pavement, before this is 
opened to traffic/use (NCHRP, 1985). In more detail, major factors affecting the effective outcome of the paving activity must be sought in design features, jointing techniques, and environmental circumstances.

Detection of the cause of early cracking is a challenging task. In maintenance practice, it is of vital importance to identify the most suitable repair action. In pavement design, it is crucial to mitigate risk of early cracking for future construction.

Within this context, comprehensive analytical methods are available in the literature to assess interactions among the above key factors for risk assessment purposes. These methods allow for identification of high-risk conditions and critical design scenarios leading to early cracking.

\section{STATEMENT OF THE PROBLEM}

Early cracking in construction management is a topic of heated debate between contracting Authorities and contractors. Cracking may be caused by unsuitable construction practice and/or unfavourable climatic conditions during concrete pouring and hardening. In this regard, it is difficult to identify legal liability between parties when damage occurs. It is worth to mention that early cracking in concrete slabs has been also reported when all construction stages (e.g., saw-cutting at the joints or identification of the optimal time interval between crafting and laying out of concrete) were correctly performed.

Within this framework, mitigating risk of early cracking by specificallyaddressed design solutions is an approach that is gaining momentum nowadays. To this effect, it is known that some of the testing methods and equipment, which are mostly focused on estimation of size of concrete slabs and stiffness of the base, may damage the pavement under investigation.

However, a more comprehensive approach suggests that early cracking in rigid pavements is due by contribution of concurrent unfavourable conditions in terms of weather, pavement design, mix design and contruction (Fig. 1). In this regard, it is advised to account for all of these factors at the design stage in order to reduce likelihood of early cracking. 


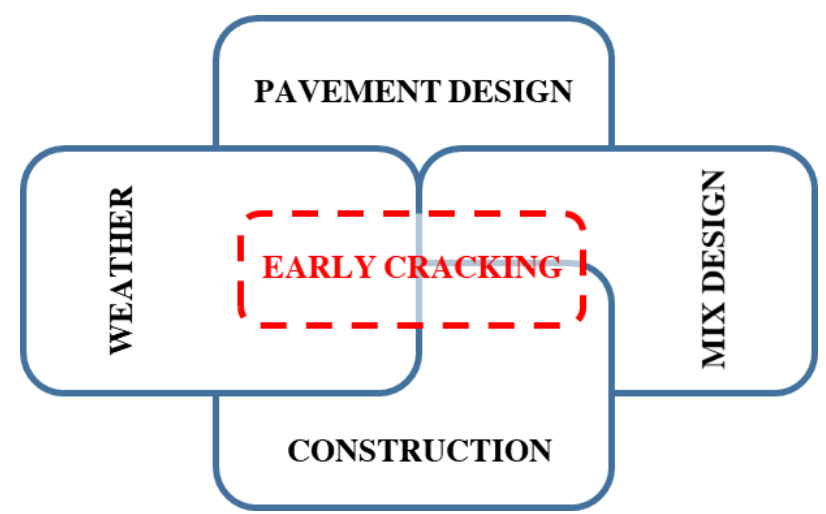

Figure 1. Main factors contributing to early cracking in rigid pavements.

Models currently applied for prediction of risk of cracking after concrete slab laying out require usually a number of detailed information. These include, among the others, actual weather and mix design conditions encountered at the concrete casting stage. Nevertheless, this level of detail cannot be reached at the design stage, as this may occur time before construction begins. In addition, mix design is usually deputed to the construction company rather than to the designer, and it must comply with specific performance requirements set by the contractor.

Within this context, design solutions usually rely on averaged data input that may not reflect actual pavement requirements and environmental conditions. Assumption of average information may increase risk of early cracking.

\section{AIM \& OBJECTIVES}

The aim of this study is to develop a probabilistic method for the assessing risk of early cracking in airfield concrete pavement design.

To achieve this aim, the following objectives have been pursued:

- to consider design and climatic parameters of the construction site as input data. Output of the model are trends of strength and stress after the laying out of concrete;

- to provide a probabilistic risk assessment of early cracking for specific design solutions.

\section{METHODOLOGY}

The proposed approach relies on the use of the HIPERPAV software (FAA, 2009). 
The strength-to-stress ratio (SRR, Lee et al, 2003) is used as a risk index for early cracking. It is defined as the minimum ratio between strength of the concrete and its internal stress at the initial setting stage (i.e., within the first 72 hours from casting). In case the SRR index is lower than one (i.e. stress is higher than strength), cracking patterns are triggered.

The main principle followed in the pavement design is to ensure an SSR value the most similar to the average SSR likely to be found during construction. However, early cracking is a complex process involving several different variables unpredictable at the design stage. In view of this, it was decided to refer to a threshold value of risk for SRR rather than complying to the test condition $S R R>1$.

In more detail, several input information are required by the model to derive the SRR value of the designed pavement. Fig. 2 lists model input data sorted as "known" and "unknown" to the designer at the design stage.

To set a methodology for probabilistic assessment of early cracking risk at the design stage, six major parameters among those reported in Fig. 1 were set to vary between fixed ranges. These ranges were representative of potential real case scenarios. Table 1 reports the values of the parameters used for the calculation of the SSR value.

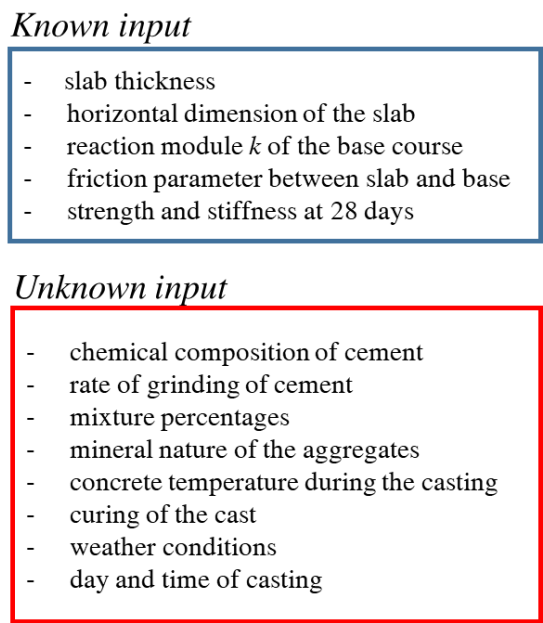

Figure 2. Input data required by HIPERPAV to perform an early cracking test.

Table 1. Range of Tested Input Parameters.

\begin{tabular}{ccccccc} 
Parameter & Latitude & $\begin{array}{c}\text { Season of } \\
\text { construction }\end{array}$ & Hour of casting & $\begin{array}{c}\text { Slab } \\
\text { thickness }\end{array}$ & $\begin{array}{c}\text { Slab } \\
\text { dimension }\end{array}$ & $\begin{array}{c}\text { Base } \\
\text { stiffness } k\end{array}$ \\
\hline Tested values & $46.6^{\circ}$ & Spring & $9.00 \mathrm{am}$ & $0.30 \mathrm{~m}$ & $3 \mathrm{~m}$ & $229 \mathrm{pci}$ \\
& $37.6^{\circ}$ & Summer & $12.00 \mathrm{am}$ & $0.40 \mathrm{~m}$ & $5 \mathrm{~m}$ & $445 \mathrm{pci}$ \\
& $33.6^{\circ}$ & $\begin{array}{c}\text { Autumn } \\
\text { Winter }\end{array}$ & $15.00 \mathrm{am}$ & & $7 \mathrm{~m}$ & $973 \mathrm{pci}$ \\
\hline
\end{tabular}


Hence, a total population of 648 combinations were generated for the simulations in HIPERPAV. To identify the most viable inputs to use for design purposes, a random set of 30 combinations was extracted out of the overall 648. Hence, the variability of the two main unknown parameters, i.e., mix design and weather conditions was observed.

\section{Mix Design}

Concrete mixture main components and their proportion highly affect the thermal history of hours following the concrete casting. In more detail, the chemical composition of the cement, fineness, composition by weight of the mixture and the nature of aggregates affect the thermal behaviour of the concrete slab.

HIPERPAV software requires to input a number of cement characteristics. These can be done by using standard Portland cements (ASTM, 2007), or by specifying cement features manually. The composition of the mixture can be defined to a similar extent. However, these information are most likely unknown to the designer during the design process.

A population of 100 different concrete mixtures was statistically generated to select the most suitable mix design. Out of this, a random group of 10 samples was extracted. In addition, 30 further random combinations out of the total 648 initial input data were selected. Hence, the SSR was calculated for each of the overall 300 combinations.

\section{Climatic Conditions}

Weather conditions at the casting of concrete are crucial to trigger early cracking. To this effect, HIPERPAV software requires various specific information on air temperature during the day, relative humidity, wind speed and cloud coverage. Hence, it is worthy to note that level of requested details is unlikely to be reached at the design phase.

Within this context, use of streamlined equations was investigated to represent the above information. It is known that air temperature and relative humidity hold a quasi-sinusoidal behaviour. In addition, it has been demonstrated that use of theoretical sinusoidal functions slightly affect temperature distribution within a concrete slab. In more detail, the Sinusoidal-Approximated Air Temperature (SAAT) and the Sinusoidal-Approximated Relative Humidity (SARH) equations were used (Qin and Hiller, 2010):

$$
\begin{aligned}
& \text { SAAT: } T_{\text {air }}(h)=\overline{T_{\text {alr }}}+\frac{\Delta \overline{T_{\text {alr }}}}{2} \cdot \sin \left(\frac{\pi}{2} \cdot(h-9)\right) \\
& \text { SARH: } R H(h)=\overline{R H}+\frac{\Delta \overline{R H}}{2} \cdot \sin \left(\frac{\pi}{2} \cdot(h-21)\right)
\end{aligned}
$$


where $h$ is the hour within the day, $\overline{\boldsymbol{T}_{\text {air }}}$ and $\overline{\boldsymbol{R} \boldsymbol{H}}$ are the average temperature of the air and the average relative humidity during the three days following the concrete casting, respectively; $\overline{\Delta \boldsymbol{T}_{\text {air }}}$ and $\overline{\Delta H R}$ are the maximum difference between average value of temperature and humidity in the same period.

Among the "latitude" and "season of construction" values reported in Tab. 1, three random combinations were generated to test the viability of the proposed streamlined functions.

As the wind speed has shown a more irregular behaviour, unlikely to be represented by a theoretical equation, it was decided to use the average value observed in the geographical area.

\section{RESULTS}

\section{Mix Design}

For each of the 30 samples of input parameter, the frequency distribution of SSR was observed with regard to the various tested mix designs, for an overall amount of 300 combinations. Samples were found to follow a normal probability distribution, as reported in Fig. 3.
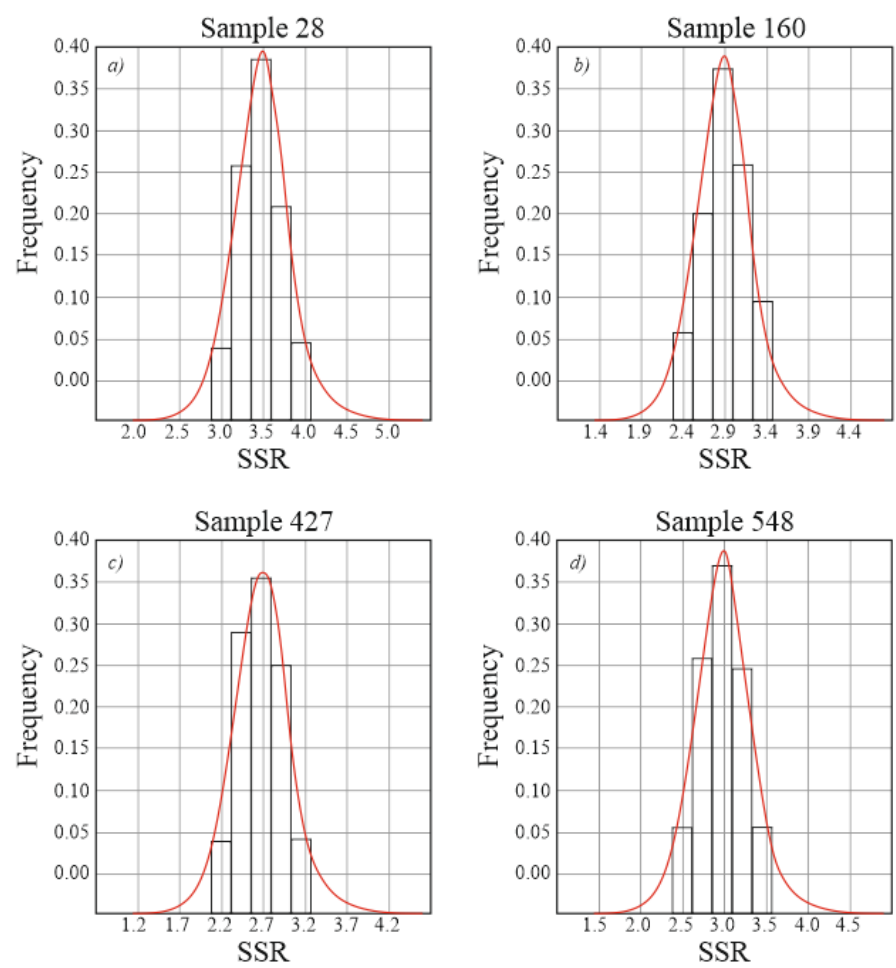

Figure 3. Examples of probability distribution analysis of SSR for samples a) 28, b) 160 , c) 427 and d) 548, randomly extracted among the combination input population. 
By assessing the mean value $\mu\left(S S R_{i}\right)$ of each $i^{\text {th }}$ input combination, out of the tested 30, with respect to the result of the adoption of the $j^{\text {th }}$ mix design, it was possible to select the mix design combination with SSR value most similar to $\overline{S S R}$. In more detail, the mix design MD4 was found to perform better, as shown in Fig. 4. The main properties of the mix design combination MD4 are reported in Tab. 2.

\section{Climatic Conditions}

To test the reliability of the proposed streamlined approach, the 30 input combinations were simulated in HIPERPAV, with climatic conditions varying among the three random scenarios reported in Tab. 3.

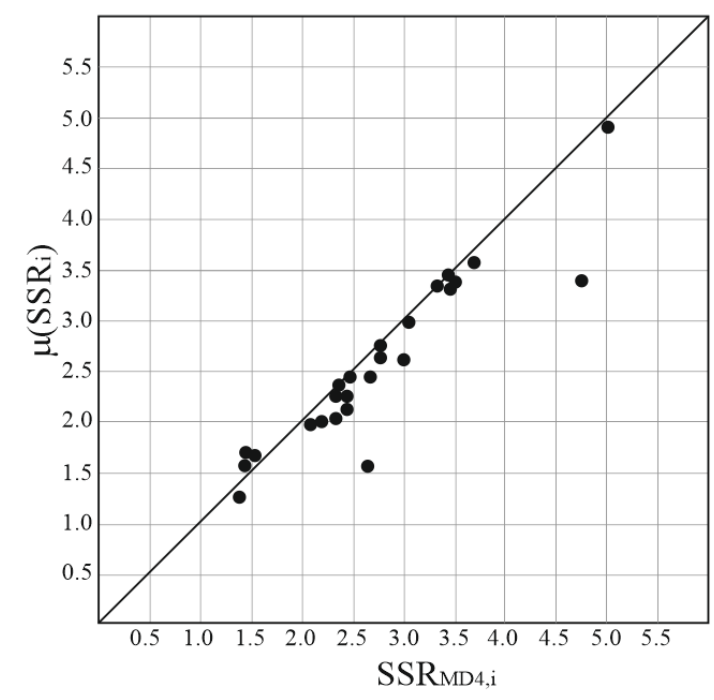

Figure 4. Dispersion plot of SSR

Table 2. Range of Tested Input Parameters.

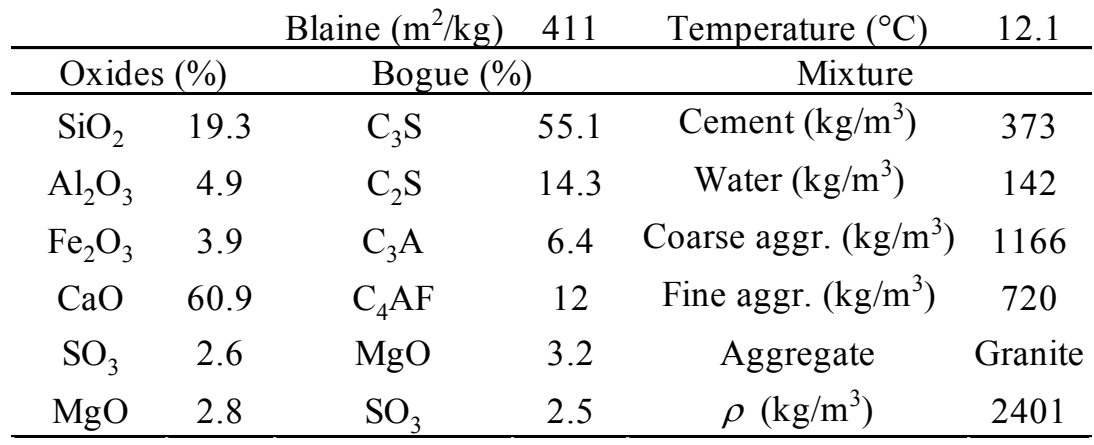


Table 3. Seasonal Features of the Randomly-generated Climatic Scenarios.

\begin{tabular}{cccc} 
Climatic Scenario & 1 & 2 & 3 \\
\hline Season & Spring & Summer & Winter \\
Latitude $\left({ }^{\circ}\right)$ & 37.6 & 46.6 & 33.6 \\
$\overline{T_{\text {air }}\left({ }^{\circ} \mathrm{C}\right)}$ & 13.05 & 23.55 & 12.65 \\
$\Delta \overline{T_{\text {air }}}\left({ }^{\circ} \mathrm{C}\right)$ & 11.9 & 13.7 & 12.9 \\
$\overline{R H}(\%)$ & 57 & 44.45 & 44.95 \\
$\Delta \overline{R H}(\%)$ & 36.4 & 36.5 & 34.5 \\
\hline
\end{tabular}

A comparison between theoretic and simulated 72 hours behavior of temperature and relative humidity is reported in Fig. 5. To this effect, a good fitting was observed between modelled data and data contained in the HIPERPAV database.
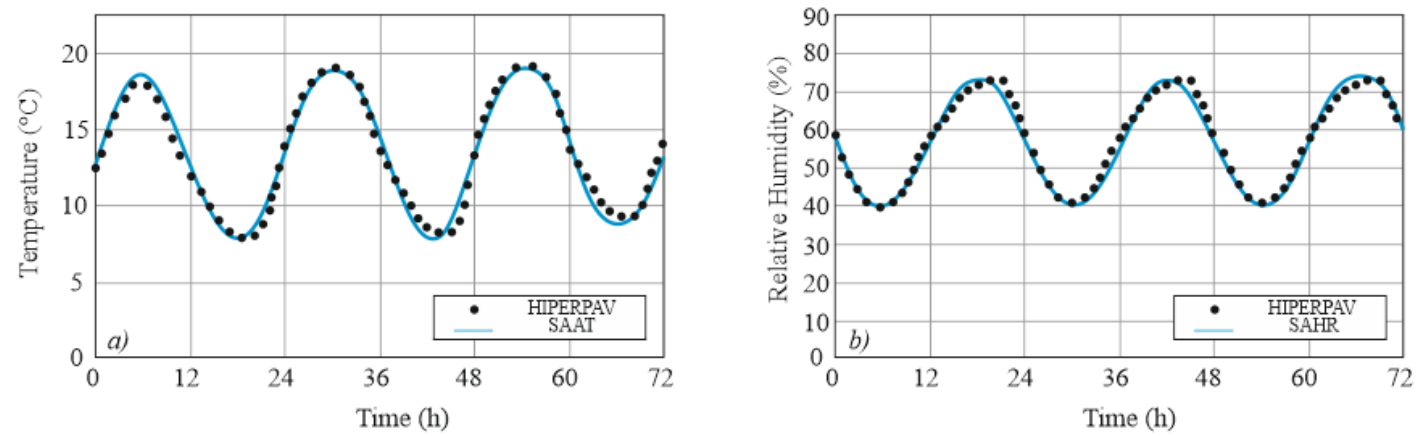

Figure 5. Comparison between the HIPERPAV simulation and the (a) SAAT and (b) SAHR application to the Climatic Scenario 1.

Examples of the outcomes from the stress/strength simulation in terms of evolution during the 72 hours of observation are instead shown in Fig. 6.
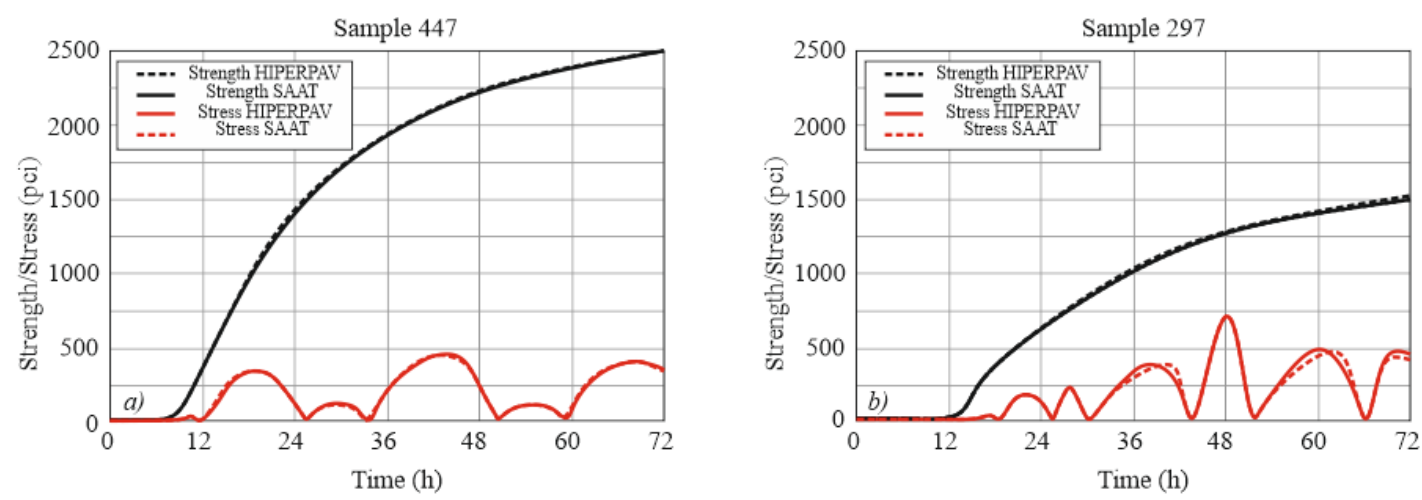

Figure 6. Comparison between the HIPERPAV simulation and the SAAT and SAHR application to the stress/strength evolution of samples (a) 447 and (b) 297. 


\section{Probabilistic Risk Assessment}

The "reliability" measure in HIPERPAV was taken into account for defining risk thresholds of early cracking $(F A A, 2009)$. This parameter represents the design effectiveness against the potential variability of the input parameters. Using a certain value of reliability, confidence level of the assessment with an accepted level of risk are set. As an example, in case a reliability of $90 \%$ is set, then it is accepted that a $10 \%$ of probability from the HIPERPAV simulation will be outside the prediction scenario.

Thereby, a value of SSR resulting from a pavement design may return different values of vulnerability to early cracking, according to the fixed reliability.

To this purpose, 30 additional samples were randomly extracted out of 648 input combinations. Trend of risk obtained by software was analysed with reference to the specific SSR. Therefore, a risk chart was produced with respect to the SSR given by the designed pavement (Fig. 7). Three levels of reliability were set for the simulations, namely, $50 \%, 75 \%$ and $90 \%$, with returned critical SSR equal to, respectively, 1.0, 1.4 and 1.8 .

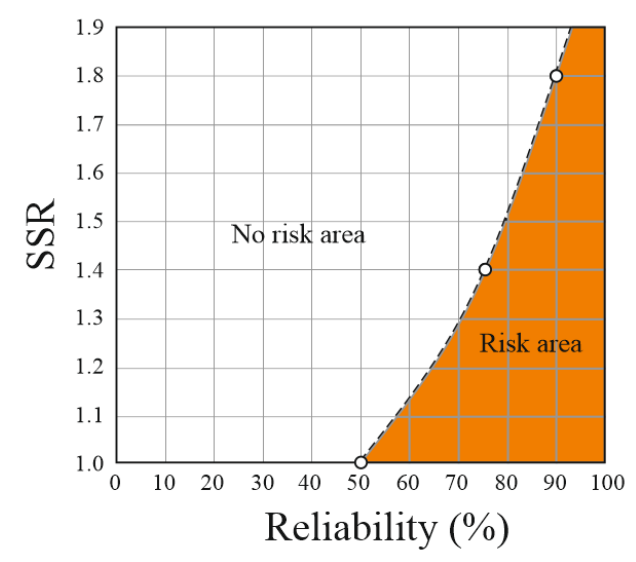

Figure 7. Chart identifying risk of early cracking for a designed pavement, as a function of SSR and required reliability.

\section{CONCLUSIONS}

This research presents a streamlined probabilistic methodology, based on the use of the HIPERPAV software, for risk assessment of early cracking in airfield concrete pavement design.

The method provides a strength-to-stress ratio (SSR) index for identification of critical cracking conditions at the design stage. To that effect, six common input parameters for simulation purposes were set to vary between fixed ranges. 
A total amount of 648 combinations of these parameters was considered for simulation in HIPERPAV. This was done for investigating the sensitivity of SSR against single parameters.

In more detail, the methodology provides information on the value to use for two major design input, i.e. mix design and climatic conditions during paving. These are usually unknown to the designer.

As a result, a risk chart is presented with reference to the designed SSR value, and the required reliability level of the design process.

\section{ACKNOWLEDGEMENT}

The authors are grateful to Ms. Alessandra Santini for the contribution given to modelling.

\section{REFERENCES}

American Concrete Pavement Association (ACPA), (1993). "Joint and Crack Sealing and Repair for Concrete Pavements", TB012P, Arlington Heights, IL.

American Concrete Pavement Association (ACPA), (1991). "Design and Construction of Joints for Concrete Highways", TB010P, Arlington Heights, IL.

ASTM C 150 (2007). "Standard specification for portland cement". American Society for Testing and Materials.

Delatte, N.J. (2014). "Concrete Pavement Design, Construction, and Performance", CRC Press.

Federal Aviation Administration (FAA), (2016). "Airport Pavement Design and Evaluation”, Advisory Circular, AC 150/5320-6F.

Federal Highway Administration (FHWA), (2009). "Computer-Based Guidelines for Concrete Pavements: HIPERPAV ® III USER MANUAL”, Publication no. FHWA-HRT-09-048.

Lee, E.B. Lamour, V. Pae, J.H. Harvey, J. (2003) "Analysis of sensitivity of plain jointed concrete pavements in California to early-age cracking using HIPERPAV". California Department of Transportation.

National Cooperative Highway Research Program, (1985). "Joint Repair Methods for Portland Cement Concrete Pavements" NCHRP report 281, TRB, Washington D.C. 
Okamoto, P., Nussbaum, P.J., Smith, K.D., Darter, M.I., Wilson, T.P., Wu, C.L., Tayabji, S.D., (1994). "Guidelines for Timing Contraction Joint Sawing and Earliest Loading for Concrete Pavements", Volume 1: Final Report, FHWA $\neg$ RD-91-079, FHWA, U.S. Department of Transportation.

Qin, Y., Hiller, J.E. (2011) "Modeling temperature distribution in rigid pavement slabs: impact of air temperature", Construction and Building Materials, 25, 9, 3753-3761.

G.F. Voigt (2002). Early cracking of concrete pavement - causes and repairs. American Concrete Pavement Association. Proceedings of 2002 Federal Aviation Administration Airport Technology Transfer Conference.

Yoder, E. J. and Witczak, M. W. (1975). "Principles of Pavement Design”, John Wiley \& Sons Ed. 